\title{
Optimization of Financial Penalties for Environmental Pollution by Chinese Traditional Energy Enterprises
}

\section{OPEN ACCESS}

Edited by:

Qiang Ji,

Institutes of Science and

Development,

Chinese Academy of Sciences, China

Reviewed by:

Decheng Wen,

Shandong University, China

Fuji Xie,

Shanghai Jiao Tong University, China

${ }^{*}$ Correspondence:

Tao Yu

yut@sdnu.edu.cn

†These authors share first authorship

Specialty section:

This article was submitted to Epigenomics and Epigenetics, a section of the journal

Frontiers in Environmental Science

Received: 25 September 2020 Accepted: 03 November 2020

Published: 30 November 2020

Citation:

Chang L, Song Y and Yu T (2020)

Optimization of Financial Penalties

for Environmental Pollution by

Chinese Traditional Energy

Enterprises

Front. Environ. Sci. 11:610152. doi: 10.3389/fenvs.2020.610152

\author{
Le Chang ${ }^{1,2+}$, Yadong Song ${ }^{1 \dagger}$ and Tao $\mathrm{Yu}^{1 *}$ \\ ${ }^{1}$ Business School, Shandong Normal University, Jinan, China, ${ }^{2}$ School of Economics and Management, Shandong \\ Agriculture and Engineering University, Jinan, China
}

The formulation of proper financial penalties plays an important role in regulating Chinese traditional energy enterprises' illegal pollution. Through the construction of a mixed-strategy game model and an evolutionary game model for regulatory agencies and traditional energy enterprises, the article studies how financial penalties impact players' strategies and evolutionary processes to optimize financial penalties. It found that excessive financial penalties could reduce enforcement, but insufficient financial penalties would cause more pollution discharge violations. The article concludes that Chinese environmental laws should focus more on setting reasonable penalties based on the profit from activities that generate illegal pollution rather than on the environmental damage to improve regulatory effectiveness.

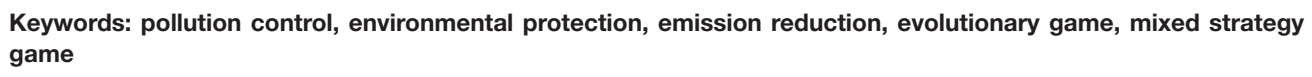
game

\section{INTRODUCTION}

The China Environmental Quality Comprehensive Evaluation Report 2018 shows that in the 20 years between 1996 and 2015, the pollution index increased from 44.52 to 137.65. Especially after 2000, the worsening of environmental pollution accelerated significantly, and traditional energy has become a major threat to the future of sustainable development (Ding et al., 2020; Wu et al., 2020). In June 2020, the Second National Pollutant Source Census Bulletin, issued by the Ministry of Ecology and Environment, the National Bureau of Statistics, and the Ministry of Agriculture and Rural Affairs, shows that in 2017, the petroleum, coal, and other fuel processing industries ranked first in the emission of volatile phenols and cyanide, at 160.39 tons and 19.78 tons, respectively. In addition, the power and heat production and supply industries ranked first in the emission of sulfur dioxide at 1.462 million tons and second in the emission of nitrogen oxide at 1.692 million tons. However, according to the European Union Emission Inventory Report 1990-2017 under the UNECE Convention on Long-Range Transboundary Air Pollution (LRTAP), in the same year European Union (EU) emissions of sulfur dioxide and nitrogen oxide were only 23.23 thousand tons and 72.35 thousand tons, respectively. The comparison between China and the EU presents the severe damage caused by traditional energy to China's environmental ecosystem. Globally, illegal discharge by traditional energy enterprises is one of the major threats to the environment. For example, in China, many thermal power plants have become the focus of the Ministry of Ecology and Environment due to their illegal discharge. In Europe, Germany, France, and three 
other countries have been warned by the European Commission about excessive nitrogen dioxide emissions, and in the United States, traditional energy enterprises are fined by the government every year for illegal discharge. Traditional energy enterprises' environmental pollution deteriorates the public's living environment (Huang et al., 2014; Guan et al., 2016), poses a threat to ecosystem (Sharma and Chatterjee, 2017), negatively affects food safety and water quality (Ramón and Lull, 2019), puts a heavy burden on healthcare and the economy (Li et al., 2016), and leads to mass incidents and the decline of government credibility (Sun et al., 2014). Effectively regulating the operation of traditional energy enterprises will transform the energy structure into new low-carbon energy and become an important part of Chinese pollution control.

Research on pollution control of traditional energy enterprises has been conducted on various impact factors, including development of artificial intelligence techniques (Ye et al., 2020), big data technology (Peng and Yang, 2020), population and energy prices (Ji et al., 2018; Li K. et al., 2019), economic growth (Ma et al., 2016; Alvarez-Herranz et al., 2017), taxation (Zimmer and Koch, 2017), energy technologies (Allevi et al., 2017; Gu et al., 2018), public awareness of sustainable development ( $\mathrm{Li}$ et al., 2021), better accessing to credit (Zhang et al., 2020), gender inequality (Li J. et al., 2019), market sentiment (Hu et al., 2020), ultra-low carbon energy (Kumar et al., 2016), renewable energy (Wang et al., 2020), and mechanism design (Yang and Yang, 2019). In addition to these impact factors, the financial penalties for traditional energy enterprises' illegal pollution discharge are not only the focus of public opinion and legislation but also one of the most important impact factors in academic research (Jin et al., 2020; Yan et al., 2020). After the 2010 Gulf of Mexico oil spill, BP was fined USD 20.8 billion, which severely impacted investors' profit expectations, causing the company's market value to shrink by more than one-third. This case reflects the deterrent effect of financial penalties on illegal pollution by traditional energy enterprises. In the same year, Zijin Mining, a Chinese company that annually earns several billion yuan in profits, caused a direct loss of USD 4.49 million (RMB 31.87 million) by polluting river water. The Fujian Provincial Environmental Protection Department fined the company only USD 1.35 million (RMB 9.56 million), which was followed by a more than $50 \%$ increase in the company's stock price (Kong et al., 2014). A comparison of the two incidents leads to reflection on the optimization of environmental pollution penalties. How can financial penalties be scientifically formulated to constitute a sufficient deterrent to enterprises' illegal polluting activities?

The updated Environmental Protection Law, implemented in China on January 1, 2015, introduced daily, accumulating fines that accrue on the day after the date of the ordered correction. According to Ministry of Ecology and Environment of the People's Republic of China, there were 186,000 environmental administrative penalties nationwide in 2018, compared to only 83,000 in 2014 , an increase of $124 \%$ in five years. The financial penalties totaled $\$ 2.15$ billion (RMB15.28 billion) in 2018, compared with only $\$ 0.45$ billion (RMB3.17 billion) in 2014, an increase of $382 \%$. The implementation of the updated Environmental Protection Law has significantly increased the financial penalties for pollution violations, but did not prevent environmental administrative penalties cases from increasing.

In academia, many scholars have explored the regulatory and financial penalties for emissions violations by traditional energy enterprises from the perspective of game model analysis. Wang and Shi (2019) developed an evolutionary game model of industrial pollution between local governments and enterprises to investigate industrial pollution problems. The results showed that under the static penalty mechanism, the strategies of local governments and enterprises are uncertain, but under the dynamic penalty mechanism, firms tend to reduce emissions when the financial penalties increase. Peng et al. (2019) established a game model for the government and enterprises to promote the implementation of a producer responsibility system. The study showed that the government should establish an inspection system to check product design, recall, and other aspects regularly or irregularly and should increase the financial penalties for non-compliance. Chen et al. (2019) examined the relationship among government, enterprises, and the public in environmental governance from the perspective of a multiplayer evolutionary game to improve environmental governance. The authors argued that regulatory effectiveness is influenced by enterprises' illegal pollution revenue, and the financial penalties for illegal pollution should be increased. Jiang et al. (2019) constructed a tripartite evolutionary game model for enterprises, local governments, and the central government, and suggested that enterprises should reduce pollution by strengthening the penalties for non-compliance. Da Silva Rocha and Salomão (2019) used an evolutionary game to construct a firm-regulator game and argued that excessive inspection costs lead to ineffective regulation. In addition, financial penalties increase firms' use of clean technologies to reduce emissions. Analyzing the tripartite game model, Sheng et al. (2020) concluded that supervision and management by the central government play a major role in environmental protection, and that increasing financial penalties and compliance incentives can encourage local governments to implement environmental regulations more effectively. Through a review of legislation and related policies at the national, local, and international levels, Feng and Liao (2016) proposed several solutions for China's air pollution problem. The improvements include clarifying the government's responsibility, increasing financial penalties, etc., Thus, many scholars believe that the financial penalties for illegal pollution should be increased.

However, some empirical studies did not find a positive relationship between financial penalties and deterrence of noncompliance. Gurley et al. (2007) argued that large financial penalties are an ethics-based method used to appease victims and are not designed to discourage corporate misconduct. Barrett et al. (2018) investigated the environmental compliance of major facilities in Michigan and found that emissions-violating operations are reduced with the imposition of financial penalties in the short term, but that financial penalties do not change firms' emissions violations in the long run. Stretesky et al. (2013) examined firm strategies in response to heavy fines imposed by the U.S. Department of Environmental Protection (EPA) over seven years. Using regressions to test firm behavior before and after fines imposed on the discharging enterprises, the 
authors described the relationship between fines and pollution violations as "weakest." Prechel and Zheng (2012) analyzed the behavior of subgroups of S\&P 500 enterprises that are required to report toxic emissions to the EPA, arguing that the amount of fines does not deter pollution rates. Almer and Goeschl (2010) concluded based on statistical analysis that although some forms of criminal sanctions have a deterrent effect, severe fine rates do not demonstrate a significant deterrent effect on environmental crime. These empirical studies showed that increasing financial penalties does not reduce illegal pollution.

The discrepancy between the empirical analysis and the game study has once again questioned how to scientifically formulate financial penalties, and whether the current legislation of financial penalties for pollution can be optimized. Some studies on environmental policy optimization suggested levying reasonable taxes, providing subsidies to enterprises (Wibulpolprasert, 2016; Lappi and Ollikainen, 2019; Park et al., 2020), develop new algorithm (Kim and Kim, 2018), or optimizing carbon emission allocation programs (Yang et al., 2020) but did not explore optimization of financial penalties. An analysis of these studies showed that the reason for this discrepancy lies in two flaws in the game studies above: the game models considered the penalties for illegal polluting enterprises as part of the revenue of the regulatory agency, ignoring the fact that the regulatory agency is represented by regulatory staffs, and the payoff maximization of regulatory staffs is not the maximization of social benefit; the regulatory agencies and the traditional energy enterprises are both game players, but the above game analyses examined only the traditional energy enterprises' strategy change as a response to the variation in financial penalties and did not simultaneously consider variations in the enforcement level as a response to the traditional energy enterprises' strategy changes.

To find out the relationship between financial penalties and the probability of non-compliance, the article explores the relationship in terms of two aspects: constructing a regulation game model of regulatory agency and traditional energy enterprise, analyzing the equilibrium and stability points of the game; and using simulation analysis to validate the game study results. Based on the current literatures, the paper also intends to provide two contributions: to fill the gap between empirical research and game research on financial penalties and to provide an explanation for why deterrence theory fails to inhibit illegal discharge in several empirical studies. By using a mixed-strategy game and an evolutionary game between regulatory agencies and traditional energy enterprises, the paper tries to optimize financial penalties for environmental pollution, which benefit the current environmental legislation, and debate the popular belief that a high financial penalty standard is a solution for limited regulatory resources.

\section{THE MODEL}

The models used in this study consider whether traditional energy enterprises' operations either adhere to legal standards and all in-house policies or fail to comply with rules and regulations for economic purposes. The regulatory agencies including environmental inspection agencies and third-party environmental inspection agencies then choose to either emphasize undeviating conformity to rules, standards, and requirements with an inspection or selectively pick and choose when to enforce the regulations.

There are two players in the pollution and enforcement game. Player 1 is the regulatory agency, and player 2 is traditional energy enterprises. The regulatory agency chooses either a strict law enforcement strategy or a loose law enforcement strategy. The choice depends on the payoff and the traditional energy enterprises' strategy. Therefore, we assume the strategy set of the regulatory agency is S1 (strict law enforcement, loose law enforcement). Traditional energy enterprises choose either compliance or non-compliance. We assume the strategy set of the traditional energy enterprises is S2 (compliance, non-compliance). Compliance means the traditional energy enterprises' operations comply strictly with the regulations, and non-compliance means traditional energy enterprises fail or refuse to comply with regulations for economic purposes. The traditional energy enterprises choose either compliance or noncompliance based on the expected utility. Strict enforcement refers to the regulatory agency's emphasis on undeviating conformity with regulations, and the regulatory agency tends to choose strict enforcement when the agency identifies a traditional energy enterprise's strategy is non-compliance. Loose enforcement happens when a regulatory agency chooses selective inspection, and regulatory agencies tend to choose loose enforcement when they identify the traditional energy enterprise's strategy is compliance.

Traditional energy enterprises' revenue from non-compliance is $G_{e}$. Suppose compliance can make a traditional energy enterprise's additional revenue $E$. The regulatory agency's strict enforcement cost is $C_{g}$, and the loose enforcement cost is 0 . The motivation for traditional energy enterprises' choosing non-compliance is the huge profit. Thus, in the study we assume $G_{e}>E$. Through strict law enforcement, traditional energy enterprises' operations can be identified by the regulatory agency, and financial penalties $P$ will be imposed on a traditional energy enterprise when non-compliance is identified. If regulatory enforcement brings good social order, the regulatory agency will be rewarded with $B_{g}$ by promoting staff or salary increment. However, if pollution is identified due to regulatory negligence, then the regulatory agency will be punished with $F_{g}$ by demoting staff or reducing their salary. The good social order or regulatory negligence can be identified through external government performance evaluation or public complains. The notations used in this study are summarized in Table 1.

Based on the discussion above, the assumptions in this study can be stated as follows:

(1) Traditional energy enterprises change strategies in response to varying payoffs. Traditional energy enterprises prefer non-compliance if regulatory agencies choose loose law enforcement. Traditional energy enterprises 
TABLE 1 | Notations and definitions used in this study.

\begin{tabular}{ll}
\hline Parameters & Description \\
\hline$R_{e}$ & Traditional energy enterprises' revenue from compliance \\
$G_{e}$ & Traditional energy enterprises' revenue from non-compliance \\
$E$ & Traditional energy enterprises' additional revenue from good \\
& reputation \\
$F_{g}$ & Financial penalties for illegal pollution \\
$B$ & Penalties for regulatory agency negligence \\
$B_{g}$ & Rewards for regulatory agency for identifying illegal pollution \\
$C_{g}$ & Rewards for regulatory agency's strict enforcement \\
$R_{g}$ & Cost of strict enforcement \\
& Regulatory agency payoff when loose law enforcement is chosen
\end{tabular}

TABLE 2 | Payoff matrix of a regulatory agency and a traditional energy enterprise mixed-strategy game.

\begin{tabular}{llll}
\hline & & \multicolumn{2}{c}{ Regulatory agency } \\
\cline { 3 - 4 } & & $\begin{array}{l}\text { Strict } \\
\text { enforcement } \boldsymbol{x}^{\prime}\end{array}$ & $\begin{array}{l}\text { Loose enforcement } \\
\mathbf{1}-\boldsymbol{x}^{\prime}\end{array}$ \\
\hline $\begin{array}{l}\text { Traditional } \\
\text { energy } \\
\text { enterprise }\end{array}$ & Compliance $y^{\prime}$ & $R_{e}+E$ & $R_{e}+E$ \\
& Non-compliance $1-y^{\prime}$ & $R_{e}+B_{g}-C_{g}$ & $R_{g}$ \\
& & $R_{g}+B_{g}+B-C_{g}$ & $R_{g}-F_{g}$ \\
\hline
\end{tabular}

prefer compliance if regulatory agencies choose strict law enforcement.

(2) Regulatory agencies are not passive receivers of changing policy. They are strategic actors who take advantage of whatever measure to attain their goal, which is not always to deter environmental pollution. If traditional energy enterprises choose non-compliance, regulatory agencies will choose strict law enforcement. If traditional energy enterprises choose compliance, regulatory agencies will prefer loose law enforcement.

\section{Mixed-strategy Game Model Between a Regulatory Agency and a Traditional Energy Enterprise}

We construct a mixed-strategy game matrix for a regulatory agency and a traditional energy enterprise as shown in Table 2. Suppose the probability of a regulatory agency choosing strict law enforcement is $x^{\prime}\left(0 \leq x^{\prime} \leq 1\right)$, and the probability of choosing loose law enforcement is $1-x^{\prime}$. The probability of a traditional energy enterprise choosing compliance is $y^{\prime}\left(0 \leq y^{\prime} \leq 1\right)$ and of choosing non-compliance is $1-y^{\prime}$.

The analysis of the mixed-strategy game based on Table 2 is as follows:

The regulatory agency's expected payoff is $E_{g}$ :

$$
E_{g}=R_{g}+x^{\prime}\left(B_{g}-C_{g}\right)+x^{\prime}\left(1-y^{\prime}\right) B-\left(1-x^{\prime}\right)\left(1-y^{\prime}\right) F_{g} .
$$

The traditional energy enterprise's expected payoff is $E_{e}$ :

$$
E_{e}=R_{e}+y^{\prime} E+\left(1-y^{\prime}\right) G_{e}-x^{\prime}\left(1-y^{\prime}\right) P .
$$

Obtaining the partial derivatives on the two formulas above, and allowing the first derivative to be 0 :

$$
\begin{gathered}
\frac{\partial E_{g}}{\partial x^{\prime}}=B_{g}-C_{g}+\left(1-y^{\prime}\right)\left(B+F_{g}\right)=0, \\
\frac{\partial E_{g}}{\partial y^{\prime}}=E-G_{e}+x^{\prime} P=0 .
\end{gathered}
$$

Solving this for $y_{0^{*}}^{\prime}$ yields $y_{0^{*}}^{\prime}=1-\frac{C_{g}-B_{g}}{B+F_{g}}$, and $y_{0^{*}}^{\prime}$ denotes the optimal probability of a traditional energy enterprise choosing compliance in the Nash equilibrium.

Proposition 1. If $C_{g}<B_{g}$, compliance is the traditional energy enterprise's pure strategy.

Proof: If $C_{g}<B_{g}$, it can be concluded that $y_{0^{*}}^{\prime}=1-$ $\frac{C_{g}-B_{g}}{B+F_{g}}>1$, which denotes a traditional energy enterprise chooses compliance in the Nash equilibrium.

Proposition 1 reveals that when the reward for strict enforcement is higher than the cost of strict enforcement, compliance is the traditional energy enterprise's pure strategy, and in this condition, financial penalties for non-compliance have no impact on the traditional energy enterprise's strategy.

Proposition 2. If $C_{g}-B_{g}>B+F_{g}$, non-compliance is the traditional energy enterprise's pure strategy.

Proof: If $C_{g}-B_{g}>B+F_{g}$, it can be concluded that $y_{0^{*}}^{\prime}=$ $1-\frac{C_{g}-B_{g}}{B+F_{g}}<0$, which denotes the traditional energy enterprise chooses non-compliance in the Nash equilibrium.

Proposition 2 reveals that when the difference between the strict law enforcement cost and the rewards for a regulatory agency's strict enforcement is higher than the sum of the rewards to regulatory agencies for identifying illegal pollution and the financial penalties for the regulatory agency's negligence, noncompliance is the traditional energy enterprise's pure strategy, and non-compliance financial penalties have no impact on the traditional energy enterprise's strategy.

Proposition 3. If $P<G_{e}-E$, then strict enforcement is the regulatory agency's pure strategy.

Proof: If $P<G_{e}-E$, it can be concluded that $x_{0^{*}}^{\prime}=\frac{G_{e}-E}{P}>$ 1 , which denotes strict enforcement is the regulatory agency's pure strategy in the Nash equilibrium.

Proposition 3 reveals that financial penalties for noncompliance have no impact on the regulatory agency's strategy when the financial penalties are lower than the difference between the compliance cost and the reputation benefit, and in this condition, the regulatory agency chooses strict enforcement.

Proposition 4. If $G_{e}-E<P$ and $0<C_{g}-B_{g}<B+F_{g}$, the Nash equilibrium of the regulatory agency and the traditional energy enterprise's mixed-strategy game model is $\left\{\left(\frac{G_{e}-E}{P}, 1-\frac{G_{e}-E}{P}\right),\left(1-\frac{C_{g}-B_{g}}{B+F_{g}}, \frac{C_{g}-B_{g}}{B+F_{g}}\right)\right\}$.

Proof: If $G_{e}-E<P$ and $0<C_{g}-B_{g}<B+F_{g}$, it can be concluded that $x_{0}^{*}=\frac{G_{e}-E}{P} \in(0,1)$, and $\quad y_{0^{*}}^{\prime}=1-\frac{C_{g}-B_{g}}{B+F_{g}} \in(0,1)$. In this condition, $\left\{\left(\frac{G_{e}-E}{P}, 1-\frac{G_{e}-E}{P}\right),\left(1-\frac{C_{g}-B_{g}}{B+F_{g}}, \frac{C_{g}-B_{g}}{B+F_{g}}\right)\right\} \quad$ is the Nash equilibrium. 
Proposition 4 reveals that in the condition $G_{e}-E<P$ and $0<C_{g}-B_{g}<B+F_{g}$, the financial penalties negatively influence the probability of strict enforcement and have no impact on the traditional energy enterprise's strategy. The factors that influence the traditional energy enterprise's strategy are $C_{g}, B_{g}, F_{g}$, and $B$. The lower $\frac{C_{g}-B_{g}}{B+F_{g}}$, the higher the probability of compliance.

Based on the four propositions above, in the regulatory agency and traditional energy enterprise mixed-strategy game, the financial penalties have no impact on the traditional energy enterprise's strategy. The financial penalties affect only the regulatory agency's strategy. If the financial penalties are less than the difference between the compliance cost and the reputation benefit, then strict enforcement is the regulatory agency's pure strategy. Otherwise, the level of enforcement will decrease as the financial penalties increase. The traditional energy enterprise's strategy is decided by four factors. They are the cost of strict enforcement, rewards for strict enforcement, rewards for identifying illegal pollution, and penalties for regulatory agency negligence.

The conclusions of many game studies on environmental regulation are consistent with deterrence theory, which suggests that traditional energy enterprises can be deterred from polluting illegally by increases in the financial penalties. However, the game analysis above shows that the variation in financial penalties does not affect the non-compliance probability of traditional energy enterprises. Does this mean that deterrence theory fails? We can find the answer by analyzing the game process. Assume that the game between a regulatory agency and a traditional energy enterprise is in Nash equilibrium. Raising the financial penalties, the game will change to disequilibrium. Based on expected payoff formulas (1) and (2), it can be seen that raising financial penalties does not immediately affect the expected payoff of the regulatory agency, and the probability of strict enforcement by the regulatory agency remains the same. However, raising the financial penalties directly reduces the expected payoff of traditional energy enterprises. In response to the decreased expected payoff, the probability of compliance by traditional energy enterprises will rise to increase the expected payoff. This response will have two immediate consequences for the expected payoff of the regulatory agency: First, the regulatory agency's expectation of a payoff from identifying illegal operations will be reduced, and the decrease in the reward expectations reduces the regulatory agency's total expected payoff. Second, the regulatory agency's expectation of punishment for negligence will decrease, and the decrease in the expected punishment increases the regulatory agency's overall expected payoff. Combining the changes in these two consequences, the regulatory agency's total expected payoff will be decreased. At this time, the regulatory agency will reduce the probability of strict enforcement to increase their expected payoff, which, in turn, reduces the probability of compliance by the traditional energy enterprise. Finally, the game reaches an equilibrium state. Therefore, when the financial penalties increase, the probability of noncompliance will first rise and then fall back to the size before the change. This also provides an explanation from a game theory perspective for the empirical investigation (Barrett et al., 2018) that financial penalties reduce illegal pollution in the short term but do not change in the long run. From the deterrence theory perspective, raising financial penalties increases the probability of compliance by the traditional energy enterprise, which, in turn, leads to higher probability of strict enforcement. As the two game players gradually reach an equilibrium state, the probability of non-compliance remains the same, and the probability of strict enforcement by the regulatory agency decreases, which offsets the deterrent effect on non-compliance. Thus, it can be concluded that raising financial penalties has no impact on the strategies of the traditional energy enterprise. This conclusion is consistent with deterrence theory.

The incentives for the regulatory agency's performance, including rewards and punishment, affect traditional energy enterprise's strategies, but these factors have no impact on regulatory agency's strategies. The higher the incentive for the regulatory agency, the more the traditional energy enterprises comply. The lower the cost of strict enforcement, the more the traditional energy enterprises comply. Based on formula (1), raising the amount of the rewards and penalties for the regulatory agency will increase the probability of strict enforcement for a better expected payoff. At the same time, raising the amount reduces the expected payoff for the traditional energy enterprise, and in turn, the probability of compliance by the traditional energy enterprise for higher expected revenue increases. This change reduces the regulatory agency's expectations of rewards but increases the expectation of punishment. Combining the two consequences, the regulatory agency's expected revenue will decrease, and as a response, it will choose to reduce the probability of strict enforcement to gain a higher expected payoff. The probability of strict enforcement by the regulatory agency remains the same before and after the game reaches equilibrium. Therefore, the rewards and penalties for the regulatory agency determine the strategies of the traditional energy enterprise instead of the regulatory agency's strategies.

Increasing financial penalties reduces the probability of strict law enforcement and then alleviates the demand for regulatory resources, which could be a solution for insufficient regulatory resources in some regions. However, the function of financial penalties is the deterrence effect on illegal discharge to ensure the healthy development of the industry, instead of breaking the capital chains of some traditional energy enterprises by imposing huge financial penalties in an opportunistic action. Therefore, to protect a booming market, high financial penalties should not be used to conserve regulatory resources.

Financial penalties not only influence the Nash equilibrium between a regulatory agency and a traditional energy enterprise but also impact the evolutionarily stable strategies of traditional energy enterprises and regulatory agencies in the long term. We examine evolutionarily stable strategies in the following section.

\section{Evolutionary Game Model Between Regulatory Agencies and Traditional Energy Enterprises}

In the regulatory agencies and traditional energy enterprises evolutionary game, suppose the proportion of regulatory 
TABLE 3 | Payoff matrix of the regulatory agencies' and traditional energy enterprises' evolutionary game.

\begin{tabular}{llll}
\hline & & \multicolumn{2}{c}{ Regulatory agencies } \\
\cline { 3 - 4 } & & $\begin{array}{l}\text { Strict } \\
\text { enforcement } \boldsymbol{x}\end{array}$ & \multicolumn{1}{c}{$\begin{array}{l}\text { Strict } \\
\text { enforcement } \boldsymbol{x}\end{array}$} \\
\hline $\begin{array}{l}\text { Traditional } \\
\text { energy }\end{array}$ & Compliance $y$ & $R_{e}+E$, & $R_{e}+E$, \\
enterprises & & $R_{g}+B_{g}-C_{g}$ & $R_{g}$ \\
& Non-compliance $1-y$ & $R_{e}+G_{e}-P$ & $R_{e}+G_{e}$, \\
& & $R_{g}+B_{g}+B-C_{g}$ & $R_{g}-F_{g}$ \\
\hline
\end{tabular}

agencies choosing strict law enforcement is $x(0 \leq x \leq 1)$ and the proportion choosing loose law enforcement is $1-x$. Suppose the proportion of traditional energy enterprises choosing compliance is $y(0 \leq y \leq 1)$, and the proportion choosing non-compliance is $1-y$. The evolutionary game matrix is shown in Table 3.

The expected payoff of regulatory agencies choosing strict enforcement is

$$
E_{11}=y\left(B_{g}-C_{g}\right)+(1-y)\left(B_{g}+B-C_{g}\right)+R_{g} .
$$

The expected payoff of regulatory agencies choosing loose enforcement is

$$
E_{12}=(1-y)\left(-F_{g}\right)+R_{g} .
$$

The mean expected payoff of the regulatory agencies is

$$
\overline{E_{1}}=x E_{11}+(1-x) E_{12} \text {. }
$$

The replicator equation of regulatory agencies choosing strict enforcement is

$$
\begin{gathered}
F(x)=\frac{d x}{d t}=x\left(E_{11}-\overline{E_{1}}\right)=x(x-1)\left(C_{g}-F_{g}+y F_{g}\right. \\
\left.-B_{g}-B+y B\right) .
\end{gathered}
$$

Let's make $F(x)=0$, and then get $x_{0}^{*}=0, x_{2}{ }^{*}=1$, and $y^{*}=1-$ $\underline{C_{g}-B_{g}} F_{g}+B$.

The expected payoff for traditional energy enterprises choosing compliance is $E_{21}=E+R_{e}$. (9)

The expected payoff for traditional energy enterprises choosing non-compliance is

$$
E_{22}=x\left(G_{e}-P\right)+(1-x) G_{e}+R_{e} .
$$

The mean expected payoff for traditional energy enterprises is $\overline{E_{2}}=y E_{21}+(1-y) E_{22}$.

The replicator equation of regulatory agencies choosing strict enforcement is

$$
F(y)=\frac{d y}{d t}=y\left(E_{21}-\overline{E 2}\right)=y(y-1)\left(G_{e}-x P-E\right) .
$$

Let's make $F(y)=0$, and get $y_{1}^{*}=0$, and $y_{2}^{*}=1, x^{*}=\frac{G_{e}-E}{P}$.

Then we can get five fine local equilibrium points of differential equation systems which are $A(0,0), B(0,1), C(1,0)$, $D(1,1)$, and $0\left(\frac{G_{e}-E}{P}, 1-\frac{C_{g}-B_{g}}{F_{g}+B}\right)$.
Based on the replicator dynamic equations $F(x)$ and $F(y)$, we get $J$ :

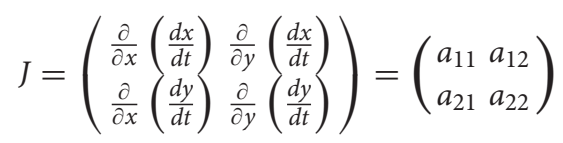

$$
=\left(\begin{array}{cc}
(2 x-1)\left(C_{g}-F_{g}-B_{g}-B+y F_{g}+y B\right) \\
y(1-y) F_{g} & (1-x)\left(B+F_{g}\right) \\
y(-1)\left(G_{e}-E-x P\right)
\end{array}\right) .
$$

Table 4 shows the system local equilibrium points.

$$
\begin{aligned}
& \lambda_{1}=\left(\frac{G_{e}-E}{P}\right)\left(\frac{G_{e}-E}{P}-1\right)\left(F_{g}+F_{e}\right), \\
& \lambda_{2}=\left(1-\frac{G_{e}-B_{g}}{F_{g}+P}\right)\left(\frac{G_{e}-B_{g}}{F_{g}+P}\right) F_{e} .
\end{aligned}
$$

When the conditions $\operatorname{tr}(J)=a_{11}+a_{22}<0$ and $\operatorname{det}(J)=$ $a_{11} a_{22}+a_{12} a_{21}>0$ are met, the equilibrium point is an evolutionarily stable strategy (ESS). The analysis of each equilibrium point follows.

Equilibrium point $0(x *, y *)$, due to $a_{11}+a_{22}=0$, does not meet condition $\operatorname{tr}(j)<0$ or $\operatorname{det}(J)>0$. Thus, it is not an ESS.

Proposition 5. If $B+F_{g}+B_{g}-C_{g}<0$, then $A(0,0)$ is an ESS.

Proof: If $B+F_{g}+B_{g}-C_{g}<0$, then the local equilibrium stability analysis is as shown in Table 5.

Proposition 5 reveals in the condition $B+F_{g}+B_{g}-C_{g}<$ 0 , loose enforcement is the regulatory agencies' evolutionarily stable strategy, and non-compliance is the traditional energy enterprises' evolutionarily stable strategy.

Proposition 6. If $B_{g}-C_{g}<0 \& G_{e}-E<0$, then $B(0,1)$ is an ESS.

Proof: If $B_{g}-C_{g}<0 \& G_{e}-E<0$, then the local equilibrium stability analysis is as shown in Table 6.

Proposition 6 reveals in the condition $B_{g}-C_{g}<$ $0 \& G_{e}-E<0$, loose enforcement is the regulatory agencies' evolutionarily stable strategy, and compliance is the traditional

TABLE 4 | Regulatory agencies' and traditional energy enterprises' evolutionary game local equilibrium points.

\begin{tabular}{lllll}
\hline Equilibrium points & $\boldsymbol{a}_{\mathbf{1 1}}$ & $\boldsymbol{a}_{\mathbf{1 2}}$ & $\boldsymbol{a}_{\mathbf{2 1}}$ & $\mathbf{a}_{\mathbf{2 2}}$ \\
\hline$A(0,0)$ & $B+F_{g}+B_{g}-C_{g}$ & 0 & 0 & $E-G_{e}$ \\
$B(0,1)$ & $B_{g}-C_{g}$ & 0 & 0 & $G_{e}-E$ \\
$C(1,0)$ & $C_{g}-B-F_{g}-B_{g}$ & 0 & 0 & $E-G_{e}+P$ \\
$D(1,1)$ & $C_{g}-B_{g}$ & 0 & 0 & $G_{e}-E-P$ \\
$0\left(x^{*}, y^{*}\right)$ & 0 & $\lambda_{1}$ & $\lambda_{1}$ & 0
\end{tabular}

TABLE 5 | Local equilibrium stability analysis in case 1.

\begin{tabular}{llll}
\hline Equilibrium points & $\operatorname{tr}(\boldsymbol{J})$ & $\operatorname{det}(\boldsymbol{J})$ & Analysis result \\
\hline$A(0,0)$ & - & + & ESS \\
$B(0,1)$ & inconclusive & - & Saddle point \\
$C(1,0)$ & inconclusive & inconclusive & Unstable \\
$D(1,1)$ & inconclusive & inconclusive & Unstable
\end{tabular}


TABLE 6 | Local equilibrium stability analysis in case 2.

\begin{tabular}{llll}
\hline Equilibrium points & $\operatorname{tr}(\boldsymbol{J})$ & $\operatorname{det}(\boldsymbol{J})$ & Analysis result \\
\hline$A(0,0)$ & inconclusive & inconclusive & Unstable \\
$B(0,1)$ & - & + & ESS \\
$C(1,0)$ & inconclusive & inconclusive & Unstable \\
$D(1,1)$ & inconclusive & - & Saddle point
\end{tabular}

TABLE 7 | Local equilibrium stability analysis in case 3.

\begin{tabular}{llll}
\hline Equilibrium points & $\boldsymbol{\operatorname { t r } ( \boldsymbol { J } )}$ & $\operatorname{det}(\boldsymbol{J})$ & Analysis result \\
\hline$A(0,0)$ & inconclusive & - & Saddle point \\
$B(0,1)$ & inconclusive & inconclusive & Unstable \\
$C(1,0)$ & - & + & ESS \\
$D(1,1)$ & inconclusive & inconclusive & Unstable
\end{tabular}

TABLE 8 | Local equilibrium stability analysis in case 4.

\begin{tabular}{llll}
\hline Equilibrium points & $\boldsymbol{\operatorname { t r } ( \boldsymbol { J } )}$ & $\operatorname{det}(\boldsymbol{J})$ & Analysis result \\
\hline$A(0,0)$ & inconclusive & inconclusive & Unstable \\
$B(0,1)$ & inconclusive & inconclusive & Unstable \\
$C(1,0)$ & inconclusive & - & Saddle point \\
$D(1,1)$ & - & + & ESS
\end{tabular}

energy enterprises' evolutionarily stable strategy. When the market order is maintained by the reputation mechanism, the non-compliant traditional energy enterprises will be eliminated by market reputation instead of regulatory agency enforcement, and financial penalties have no impact on the traditional energy enterprises' strategy. However, illegal pollution has a very limited impact on traditional energy enterprises' product sales; therefore, the economic gain from illegal pollution is always higher than the reputation benefit, which is $G_{e}>E$. Thus, we do not examine this point.

Proposition 7. If $C_{g}-B-F_{g}-B_{g}<0$ and $E-G_{e}+P<0$, then $C(1,0)$ is an ESS.

Proof: If $C_{g}-B-F_{g}-B_{g}<0$ and $E-G_{e}+P<0$, then the local equilibrium stability analysis is as shown in Table 7.

Proposition 7 reveals in the condition $C_{g}-B-F_{g}-B_{g}<$ 0 and $E-G_{e}+P<0$, strict enforcement is the regulatory agencies' evolutionarily stable strategy, and non-compliance is the traditional energy enterprises' evolutionarily stable strategy.

Proposition 8 . If $C_{g}-B_{g}<0 \& G_{e}-E-P<0$, then

$D(1,1)$ is an ESS.

Proof: If $C_{g}-B_{g}<0 \& G_{e}-E-P<0$, then the local equilibrium stability analysis is as shown in Table 8.

Proposition 8 reveals in the condition $C_{g}-B_{g}<0 \& G_{e}-$ $E-P<0$, strict enforcement is the regulatory agencies' evolutionarily stable strategy, and compliance is the traditional energy enterprises' evolutionarily stable strategy.

The evolutionary analysis above shows that if strict regulatory costs are too high, financial penalties do not influence the evolutionary result, and traditional energy enterprises prefer illegal discharge. Therefore, it is important to reduce law enforcement costs by optimizing the information structure of environmental law enforcement. When the cost of strict law enforcement is lower than a certain range, the financial penalties determine the evolutionary strategy of traditional energy enterprises. If the penalty is below $G_{e}-E$, regulatory agencies prefer strict law enforcement, while traditional energy enterprises choose non-compliance. This is a phenomenon of management by penalty. In this scenario, financial penalties become the prices for illegal discharge, which encourages non-compliance by traditional energy enterprises. Although regulatory agencies work hard to enforce the law, they collect only much in terms of financial penalties and do not change traditional energy enterprises' illegal discharge actions. If the financial penalties are higher than $G_{e}-E$, regulatory agencies choose strict law enforcement and traditional energy enterprises are inclined to comply.

Based on the two game model analyses above, we draw the following conclusions.

First, in the game, the amount of financial penalties has no impact on the traditional energy enterprises' strategy, but increasing financial penalties will decrease the regulatory agencies' probability of strict enforcement. In the case of $G_{e}-$ $E \geq P$, the enforcement strategy will be evolutionarily stable at strict enforcement. For the evolution of the game, the

TABLE 9 | The parameter settings.

\begin{tabular}{lccc}
\hline Parameters & Values (\$) & Parameters & Values (\$) \\
\hline$P$ & 20,000 & $F_{g}$ & 1,000 \\
$B_{g}$ & 2,000 & $B$ & 1,000 \\
$C_{e}$ & 10,000 & $R_{g}$ & 4,000 \\
$C_{g}$ & 2,000 & $E$ & 5,000
\end{tabular}

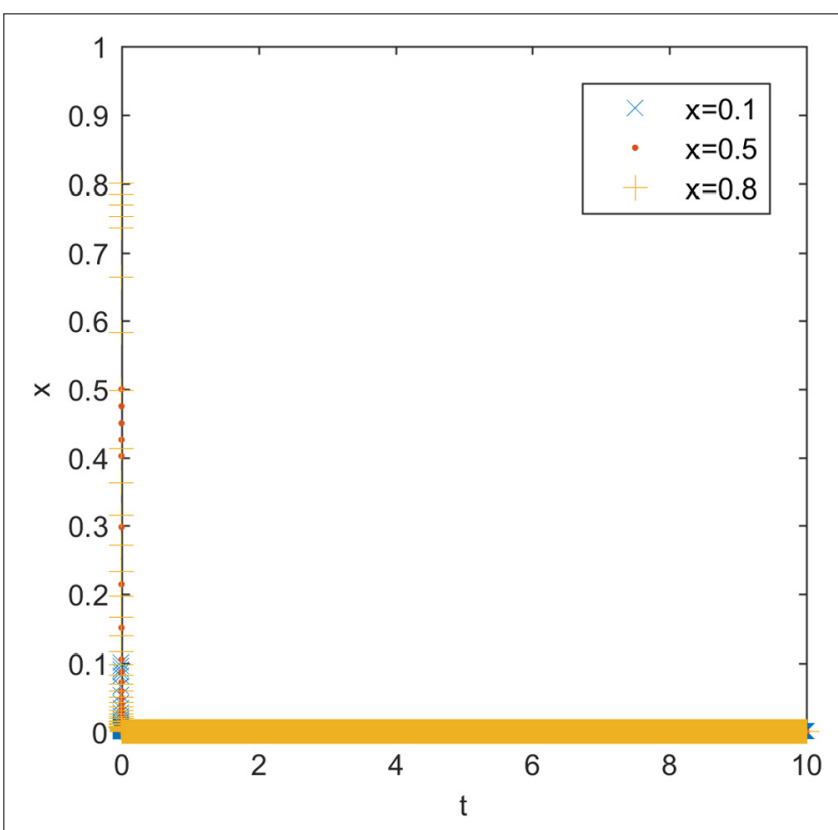

FIGURE 1 $\mid G_{e}-E \geq P$ traditional energy enterprises' evolutionarily stable strategy. 
amount of financial penalties $F_{e}$ will impact the evolutionary stability result. In the case of $C_{g}-B_{g}<0$, the reward for strict enforcement is higher than the cost of strict enforcement; if $G_{e}-E \geq P$, then $C(1,0)$ is an ESS. However, if $G_{e}-E \geq P$, then $D(1,1)$ is an ESS.

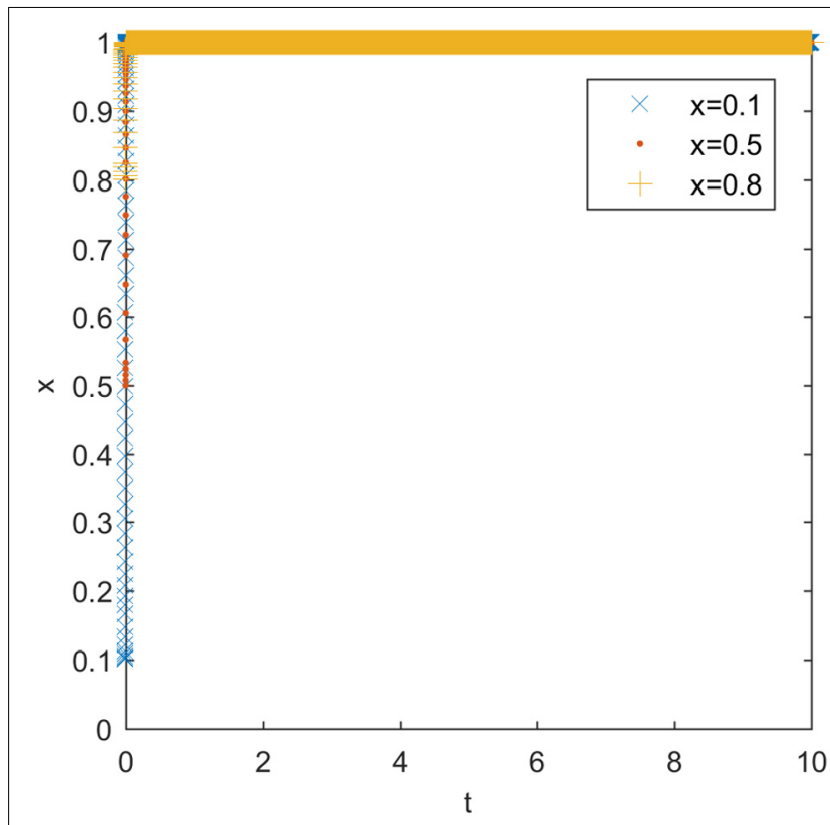

FIGURE $2 \mid G_{e}-E<P$ traditional energy enterprises' evolutionarily stable strategy.

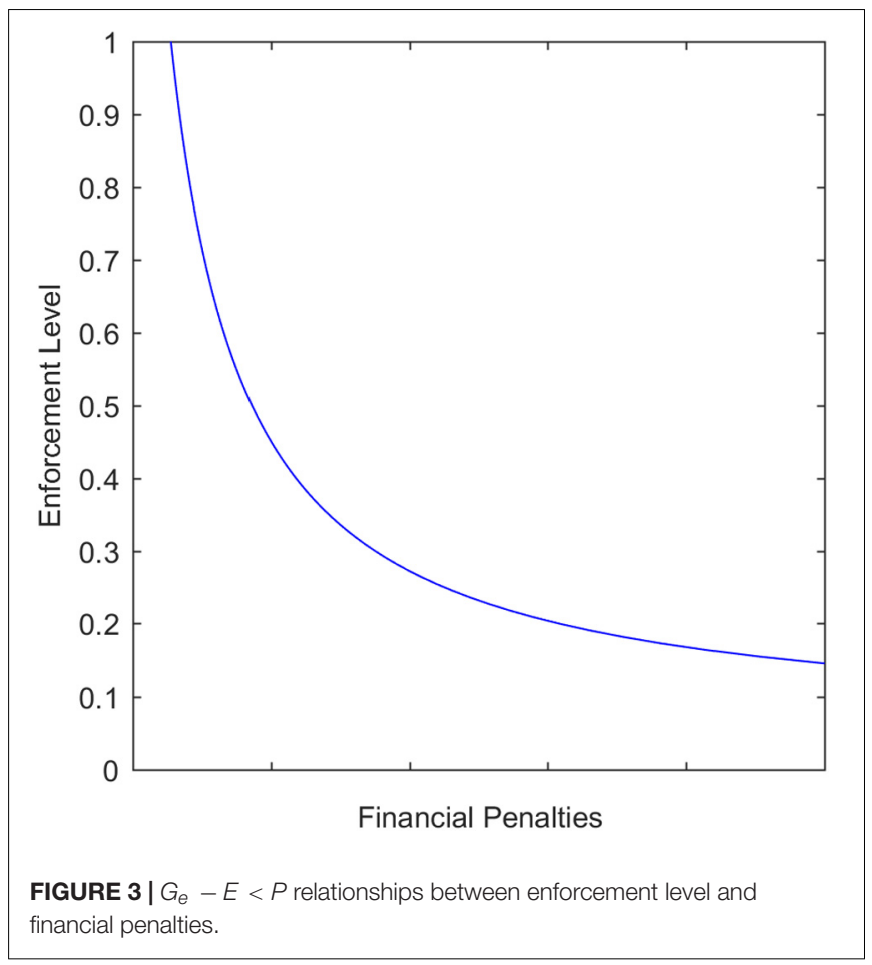

Second, in addition to $P$, the other control factors are $C_{g}$ and $B_{g}$. When the strict enforcement cost is lower than the reward $C_{g}-B_{g}<0$, the traditional energy enterprise's strategy is stable at compliance, and the enforcement strategy is stable at strict enforcement. If $0<C_{g}-B_{g}<B+F_{g}$, the probability of compliance will increase with the decrease in $C_{g}-B_{g}$, but in this condition, the traditional energy enterprise's strategy will be unstable at compliance.

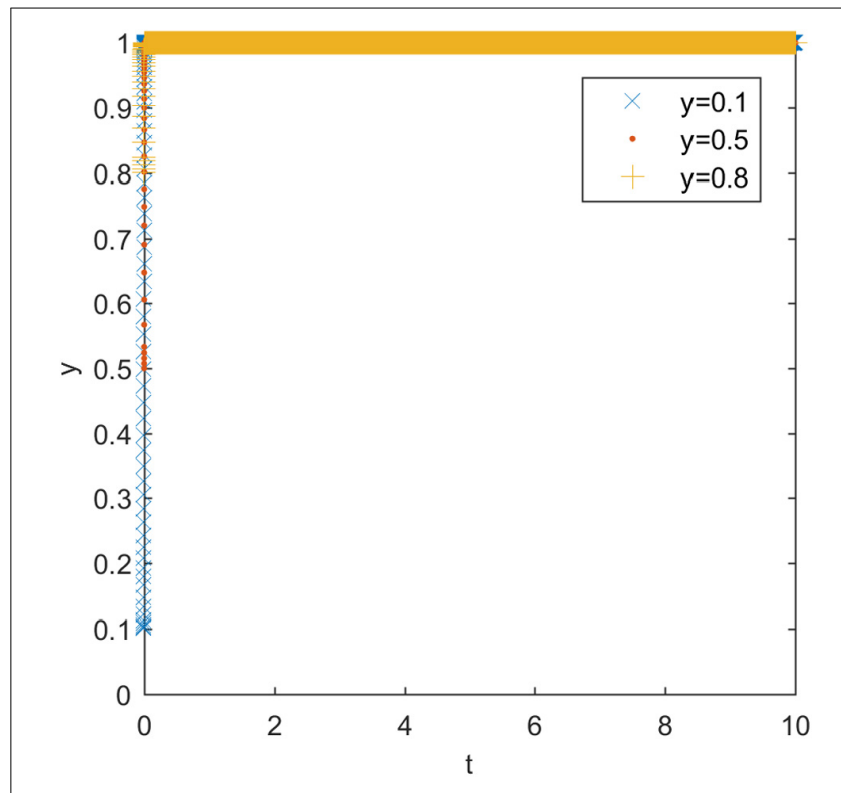

FIGURE $4 \mid C_{g}-B_{g}<0$ regulatory agencies' evolutionarily stable strategy.

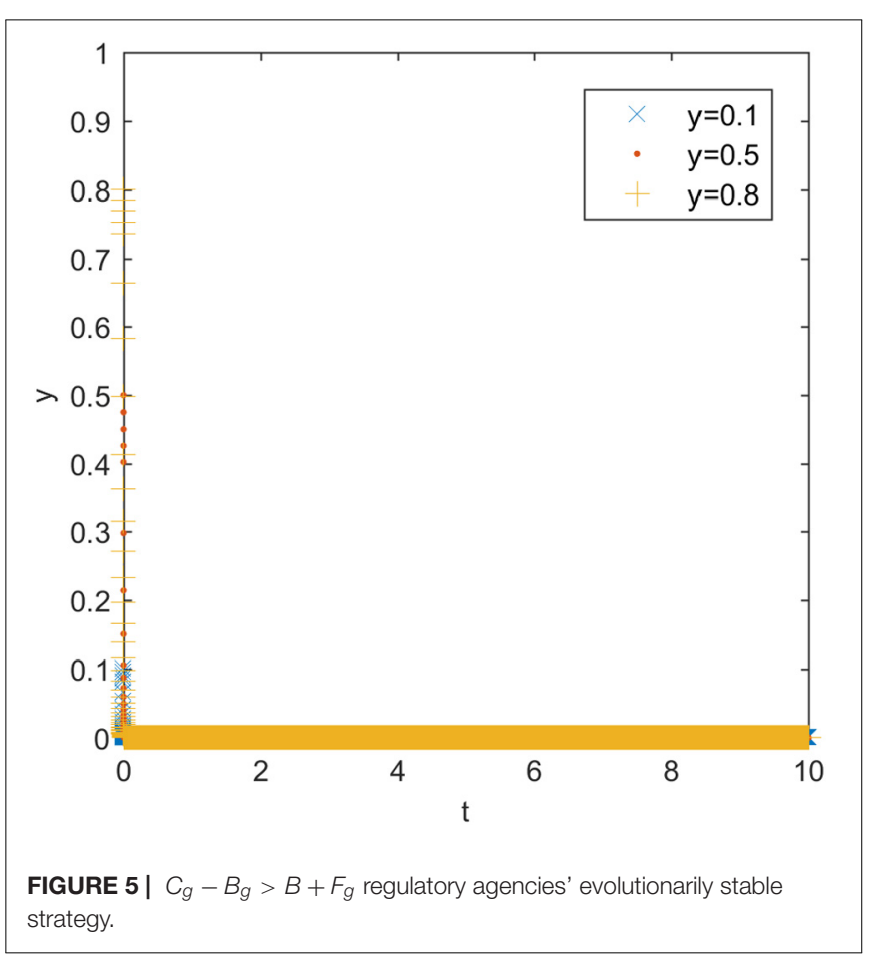




\section{SIMULATIONS WITH NUMERICAL APPLICATIONS}

Based on the game analysis above, we conduct a simulation analysis of $P, C_{g}$, and $B_{g}$. Suppose that a traditional energy enterprise complies with the regulation, with sales revenue of $\$ 20,000$, and the reputation benefit is $\$ 5,000$. If the traditional energy enterprise violates the regulation through illegal environmental pollution, the economic gain is $\$ 10,000$. The regulatory agency conducts an inspection of the traditional energy enterprise's operation. The budget for the regulatory agency is $\$ 4,000$ for loose enforcement. The cost of strict law enforcement is $\$ 2,000$ more than the cost of loose law enforcement. A $\$ 2,000$ reward to the regulatory agency is for strict enforcement. If the regulatory agency identifies noncompliance by the traditional energy enterprise, the agency will be rewarded an additional $\$ 1,000$. However, if the regulatory agency overlooks the violation due to loose enforcement, the agency will be penalized $\$ 1,000$. Table 9 shows the parameter settings for the regulatory agency and the traditional energy enterprise.

\section{Simulation Analysis of $\boldsymbol{P}$}

When $G_{e}-E \geq P$, suppose $P$ is $\$ 4,000$, and the traditional energy enterprises' strategy evolution is as shown in Figure $\mathbf{1 .}$ It illustrates when the financial penalties for non-compliance are lower than the sum of the compliance cost saving and the reputation benefit, the fraction of the traditional energy enterprises choosing compliance will evolve to 0 . This proves that if the financial penalties settings are low, then the traditional energy enterprises' evolutionarily stable strategy is non-compliance.

When $G_{e}-E<P$, suppose $P$ is $\$ 6,000$, and the evolution of the traditional energy enterprises' strategy is as shown in Figure 2. It illustrates that when the financial penalties are higher than the difference between the compliance cost and the reputation benefit, compliance is traditional energy enterprises' evolutionarily stable strategy, and the amount of financial penalties has no impact on the evolution speed and result.

In the condition $G_{e}-E<P$, the relationship between financial penalties and a regulatory agency's enforcement level is as shown in Figure 3. It illustrates that in the mixed-strategy game, the probability of strict enforcement will decrease as the financial penalties for non-compliance increase. This means financial penalties suppress non-compliance in the traditional energy enterprise's group evolutionary result, do not impact the rational individual traditional energy enterprise's strategy, and negatively correlate with the regulatory agency's probability of strict enforcement. Therefore, the optimized amount of financial penalties should be slightly higher than $C_{e}-E$.

\section{Simulation Analysis of $\boldsymbol{C}_{\boldsymbol{g}}$ and $\boldsymbol{B}_{\boldsymbol{g}}$}

When $C_{g}-B_{g}<0$, the regulatory agencies' evolutionarily stable strategy is as shown in Figure 4. It illustrates that if the cost is lower than the reward for strict enforcement by the regulatory agencies, then their evolutionarily stable strategy is strict enforcement.

When $C_{g}-B_{g}>B+F_{g}$, the regulatory agencies' evolutionarily stable strategy is as shown in Figure 5. It illustrates that when the difference between the cost and the reward in strict enforcement is higher than the sum of the penalties for negligence and the reward for identifying non-compliance, there is no incentive for strict enforcement, and the regulatory agencies' evolutionarily stable strategy is loose enforcement.

\section{CONCLUSION}

In regulation studies on environmental pollution by Chinese traditional energy enterprises, conventional game studies and legislation suggest that increasing financial penalties would effectively deter illegal pollution. However, the results from empirical studies show very different conclusions. After identifying the flaws in conventional game studies, in this paper we construct a mixed-strategy game model and an evolutionary game model between regulatory agencies and traditional energy enterprises. Through analyzing the Nash equilibrium and the evolutionarily stable strategy, we optimize the amount of financial penalties to enforce compliance by traditional energy enterprises. The analysis shows the regulatory agencies' enforcement level decreases as the financial penalties increase. As traditional energy enterprises are more sensitive to the frequency of enforcement than to the amount of the financial penalties, an increase in financial penalties may worsen the environmental pollution control. In the evolutionary game study, the traditional energy enterprises' strategy is evolutionarily stable in compliance only if the financial penalties reach a certain level. Based on the two game model studies, the optimized financial penalties should consider maximizing the probability of regulatory agencies' legal enforcement and ensuring that traditional energy enterprises' evolutionarily stable strategy is compliance.

The final conclusions are as follows. To effectively prevent traditional energy enterprises from performing illegal polluting activities, financial penalties should be set slightly higher than the difference between the economic gain from non-compliance and the reputation benefit from compliance. The rewards for regulatory agencies should be set higher than the cost of strict enforcement, to ensure regulatory agencies' evolutionarily stable strategy is strict enforcement, and traditional energy enterprises' evolutionarily stable strategy is compliance.

China's Water Pollution Prevention and Control Law, revised in 2008, stipulates that for general or large water pollution incidents, financial penalties are calculated at $20 \%$ of the direct loss, and for serious and large accidents, financial penalties are calculated at $30 \%$ of the direct losses. The Law on Prevention and Control of Air Pollution (draft for comments) stipulates that financial penalties for ordinary or large air pollution accidents shall be calculated at more than one time and less than three times the direct damage, and financial penalties for serious and very large accidents shall be calculated at more than three times and less than five times the direct damage. The updated Environmental Protection Law, implemented in China on January 1, 2015, 
introduced daily, accumulating fines that accrue on the day after the date of the ordered correction. The laws are considered to have significantly increased the financial penalties for pollution violation. According to these environmental protection laws, the financial penalties for pollution are calculated based on the damage to the environment, which contradicts the conclusions of the studies above. If the profit from long-term illegal pollution is much higher than the damage to society, then the financial penalties for traditional energy enterprises will become the price of illegal pollution. Therefore, the Zijin Mining stock price rose more than $50 \%$ after the company was punished. The reason is that the financial penalties were calculated based on the damage to society, and the long-term revenue from the illegal use of high-risk sodium cyanide in the gold refining process has been ignored. If the financial penalties for pollution are increased without restrictions, it will not only cause loose enforcement by the regulatory agencies but also fail to curb the problem of illegal discharge. Therefore, financial penalties for pollution should consider not only the environmental losses but also the illegal revenue from pollution.

\section{DATA AVAILABILITY STATEMENT}

The original contributions presented in the study are included in the article/supplementary material, further inquiries can be directed to the corresponding author.

\section{REFERENCES}

Allevi, E., Oggioni, G., Riccardi, R., and Rocco, M. (2017). Evaluating the carbon leakage effect on cement sector under different climate policies. J. Clean. Prod. 163, 320-337. doi: 10.1016/j.jclepro.2015.12.072

Almer, C., and Goeschl, T. (2010). Environmental crime and punishment: empirical evidence from the German penal code. Land Econ. 86, 707-726. doi: 10.3368/le.86.4.707

Alvarez-Herranz, A., Balsalobre-Lorente, D., Shahbaz, M., and Cantos, J. M. (2017). Energy innovation and renewable energy consumption in the correction of air pollution levels. Energy Policy 105, 386-397. doi: 10.1016/j.enpol.2017.03.009

Barrett, K. L., Lynch, M. J., Long, M. A., and Stretesky, P. B. (2018). Monetary penalties and noncompliance with environmental laws: a mediation analysis. Am. J. Crim. Justice 43, 530-550. doi: 10.1007/s12103-017-9428-0

Chen, Y., Zhang, J., Tadikamalla, P. R., and Gao, X. (2019). The relationship among government, enterprise, and public in environmental governance from the perspective of multi-player evolutionary game. Int. J. Environ. Res. Public Health 16:3351. doi: 10.3390/ijerph16183351

Da Silva Rocha, A. B., and Salomão, G. M. (2019). Environmental policy regulation and corporate compliance in evolutionary game models with well-mixed and structured populations. Eur. J. Oper. Res. 279, 486-501. doi: 10.1016/j.ejor.2019. 05.040

Ding, L. L., Liang, L., Zhao, X., and Calin, A. C. (2020). Modelling energy and carbon emission performance: a constrained performance index measure. Energy 2020:117274. doi: 10.1016/j.energy.2020.117274

Feng, L., and Liao, W. (2016). Legislation, plans, and policies for prevention and control of air pollution in China: achievements, challenges, and improvements. J. Clean. Prod. 112, 1549-1558. doi: 10.1016/j.jclepro.2015.08.013

Gu, A., Teng, F., and Feng, X. (2018). Effects of pollution control measures on carbon emission reduction in China: evidence from the 11th and 12th Five-year plans. Clim. Policy 18, 198-209. doi: 10.1080/14693062.2016.125 8629

Guan, W. J., Zheng, X. Y., Chung, K. F., and Zhong, N. S. (2016). Impact of air pollution on the burden of chronic respiratory diseases in China:

\section{AUTHOR CONTRIBUTIONS}

TY performed concept development, analysis, and writing. LC and YS performed modeling, simulation, and writing. All authors contributed to the article and approved the submitted version.

\section{FUNDING}

The research is funded by Key Project of Chinese National Funding of Social Science under Grant [13AGL012], the Natural Foundation of Shandong Province [ZR2016GM10 and ZR2017QG003], and the Social Science Foundation of Shandong Province [17DGLJ09].

\section{ACKNOWLEDGMENTS}

We would like to thank reviewers and the editor-in-charge for valuable time on the article. And we are grateful to be able to complete this article with funding from the National Social Science Foundation of China, National Social Science Foundation of China, and the Social Science Foundation of Shandong Province.

time for urgent action. Lancet 388, 1939-1951. doi: 10.1016/S0140-6736(16)31 597-5

Gurley, K., Wood, P., and Nijhawan, I. (2007). The effect of punishment on ethical behavior when personal gain is involved. J. Legal Ethical Regul. Issues 10:91.

$\mathrm{Hu}$, M., Zhang, D., Ji, Q., and Wei, L. (2020). Macro factors and the realized volatility of commodities: a dynamic network analysis. Resour. Policy 68:101813. doi: 10.1016/j.resourpol.2020.101813

Huang, R. J., Zhang, Y., Bozzetti, C., Ho, K. F., Cao, J. J., Han, Y., et al. (2014). High secondary aerosol contribution to particulate pollution during haze events in China. Nature 514, 218-222. doi: 10.1038/nature13774

Ji, Q., Liu, B. Y., Nehler, H., and Uddin, G. S. (2018). Uncertainties and extreme risk spillover in the energy markets: a time-varying copula-based CoVaR approach. Energy Econ. 76, 115-126. doi: 10.1016/j.eneco.2018.10.010

Jiang, K., You, D., Merrill, R., and Li, Z. (2019). Implementation of a multiagent environmental regulation strategy under Chinese fiscal decentralization: an evolutionary game theoretical approach. J. Clean. Prod. 214, 902-915. doi: 10.1016/j.jclepro.2018.12.252

Jin, Y., Cheng, C., and Zeng, H. (2020). Is evil rewarded with evil? The market penalty effect of corporate environmentally irresponsible events. Bus. Strategy Environ. 29, 846-871. doi: 10.1002/bse.2403

Kim, S. W., and Kim, M. H. (2018). Fuel-optimal thrust-allocation algorithm using penalty optimization programing for dynamic-positioning-controlled offshore platforms. Energies 11:2128. doi: 10.3390/en11082128

Kong, D., Liu, S., and Dai, Y. (2014). Environmental policy, company environment protection, and stock market performance: evidence from China. Corp. Soc. Responsib. Environ. Manag. 21, 100-112. doi: 10.1002/csr.1306

Kumar, A., Patil, R. S., Dikshit, A. K., Islam, S., and Kumar, R. (2016). Evaluation of control strategies for industrial air pollution sources using American Meteorological Society/Environmental Protection Agency Regulatory Model with simulated meteorology by Weather Research and Forecasting Model. J. Clean. Prod. 116, 110-117. doi: 10.1016/j.jclepro.2015.12.079

Lappi, P., and Ollikainen, M. (2019). Optimal environmental policy for a mine under polluting waste rocks and stock pollution. Environ. Resour. Econ. 73, 133-158. doi: 10.1007/s10640-018-0253-9 
Li, J., Zhang, J., Zhang, D., and Ji, Q. (2019). Does gender inequality affect household green consumption behaviour in China? Energy Policy 135:111071. doi: 10.1016/j.enpol.2019.111071

Li, K., Fang, L., and He, L. (2019). How population and energy price affect China's environmental pollution? Energy Policy 129, 386-396. doi: 10.1016/j.enpol. 2019.02.020

Li, S., Williams, G., and Guo, Y. (2016). Health benefits from improved outdoor air quality and intervention in China. Environ. Pollut. 214, 17-25. doi: 10.1016/j. envpol.2016.03.066

Li, X., Zhang, D., Zhang, T., Ji, Q., and Lucey, B. (2021). Awareness, energy consumption and pro-environmental choices of Chinese households. J. Clean. Prod. 279:123734. doi: 10.1016/j.jclepro.2020.123734

Ma, Y. R., Ji, Q., and Fan, Y. (2016). Spatial linkage analysis of the impact of regional economic activities on PM2. 5 pollution in China. J. Clean. Prod. 139, 1157-1167. doi: 10.1016/j.jclepro.2016.08.152

Park, K., Yoon, T., Shim, C., Kang, E., Hong, Y., and Lee, Y. (2020). Beyond strict regulations to achieve environmental and economic health-an optimal PM2.5 Mitigation Policy for Korea. Int. J. Environ. Res. Public Health 17:5725. doi: 10.3390/ijerph17165725

Peng, B., Wang, Y., Elahi, E., and Wei, G. (2019). Behavioral game and simulation analysis of extended producer responsibility system's implementation under environmental regulations. Environ. Sci. Pollut. Res. 26, 17644-17654. doi: 10. 1007/s11356-019-05215-w

Peng, Y., and Yang, P. (2020). Innovative application of environmental pollution control in the background of big data of business economy. Fresenius Environ. Bull. 29, 1063-1074.

Prechel, H., and Zheng, L. (2012). Corporate characteristics, political embeddedness and environmental pollution by large US corporations. Soc. Forces 90, 947-970. doi: 10.2307/41682684

Ramón, F., and Lull, C. (2019). Legal measures to prevent and manage soil contamination and to increase food safety for consumer health: the case of Spain. Environ. Pollut. 250, 883-891. doi: 10.1016/j.envpol.2019. 04.074

Sharma, S., and Chatterjee, S. (2017). Microplastic pollution, a threat to marine ecosystem and human health: a short review. Environ. Sci. Pollut. Res. 24, 21530-21547. doi: 10.1007/s11356-017-9910-8

Sheng, J., Zhou, W., and Zhu, B. (2020). The coordination of stakeholder interests in environmental regulation: lessons from China's environmental regulation policies from the perspective of the evolutionary game theory. J. Clean. Prod. 249:119385. doi: 10.1016/j.jclepro.2019.119385

Stretesky, P. B., Long, M. A., and Lynch, M. J. (2013). Does environmental enforcement slow the treadmill of production? The relationship between large monetary penalties, ecological disorganization and toxic releases within offending corporations. J. Crime Justice 36, 233-247. doi: 10.1080/0735648X. 2012.752254
Sun, Y., Jiang, Q., Wang, Z., Fu, P., Li, J., Yang, T., et al. (2014). Investigation of the sources and evolution processes of severe haze pollution in Beijing in January 2013. J. Geophys. Res. Atmos. 119, 4380-4398. doi: 10.1002/2014JD021641

Wang, C., and Shi, F. (2019). An evolutionary game model for industrial pollution management under two punishment mechanisms. Int. J. Environ. Res. Public Health. 16:2775. doi: 10.3390/ijerph16152775

Wang, Y., Zhang, D., Ji, Q., and Shi, X. (2020). Regional renewable energy development in China: a multidimensional assessment. Renew. Sust. Energ. Rev. 124:109797. doi: 10.1016/j.rser.2020.109797

Wibulpolprasert, W. (2016). Optimal environmental policies and renewable energy investment: evidence from the Texas electricity market. Clim. Chang. Econ. 7:1650010. doi: 10.1142/S201000781650010X

Wu, H., Xu, L., Ren, S., Hao, Y., and Yan, G. (2020). How do energy consumption and environmental regulation affect carbon emissions in China? New evidence from a dynamic threshold panel model. Resour. Policy 67:101678. doi: 10.1016/ j.resourpol.2020.101678

Yan, Y., Zhang, X., Zhang, J., and Li, K. (2020). Emissions trading system (ETS) implementation and its collaborative governance effects on air pollution: the China story. Energy Policy 138:111282. doi: 10.1016/j.enpol.2020.111282

Yang, M., Hou, Y., Ji, Q., and Zhang, D. (2020). Assessment and optimization of provincial CO2 emission reduction scheme in China: an improved ZSG-DEA approach. Energy Econ. 91:104931. doi: 10.1016/j.eneco.2020.104931

Yang, Y., and Yang, W. (2019). Does whistleblowing work for air pollution control in China? A study based on three-party evolutionary game model under incomplete information. Sustainability 11:324. doi: 10.3390/su11020324

Ye, Z., Yang, J., Zhong, N., Tu, X., Jia, J., and Wang, J. (2020). Tackling environmental challenges in pollution controls using artificial intelligence: a review. Sci. Total Environ. 699:134279. doi: 10.1016/j.scitotenv.2019.134279

Zhang, D., Li, J., and Ji, Q. (2020). Does better access to credit help reduce energy intensity in China? Evidence from manufacturing firms. Energy Policy 145:111710. doi: 10.1016/j.enpol.2020.111710

Zimmer, A., and Koch, N. (2017). Fuel consumption dynamics in Europe: tax reform implications for air pollution and carbon emissions. Transp. Res. Part A Policy Pract. 106, 22-50. doi: 10.1016/j.tra.2017.08.006

Conflict of Interest: The authors declare that the research was conducted in the absence of any commercial or financial relationships that could be construed as a potential conflict of interest.

Copyright (c) 2020 Chang, Song and Yu. This is an open-access article distributed under the terms of the Creative Commons Attribution License (CC BY). The use, distribution or reproduction in other forums is permitted, provided the original author(s) and the copyright owner(s) are credited and that the original publication in this journal is cited, in accordance with accepted academic practice. No use, distribution or reproduction is permitted which does not comply with these terms. 